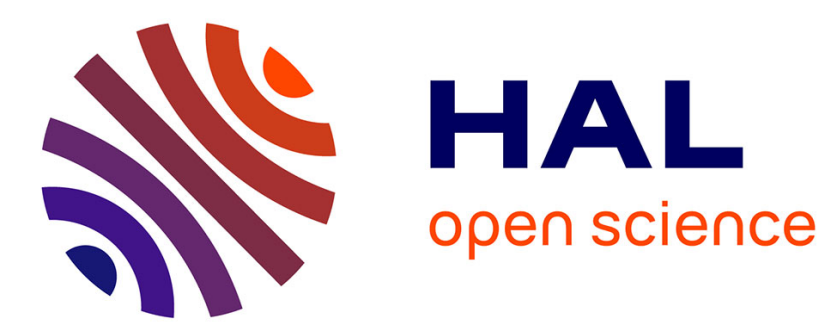

\title{
Revisiting Entrepreneurial Risk Taking: Combined Effects of Cognitive Heuristics
}

\author{
Saulo D. Barbosa, Alain Fayolle
}

\section{To cite this version:}

Saulo D. Barbosa, Alain Fayolle. Revisiting Entrepreneurial Risk Taking: Combined Effects of Cognitive Heuristics. Academy of Management Annual Meeting Proceedings, 2010, 2010 (1), pp.1-6 P. hal-02276688

\section{HAL Id: hal-02276688 \\ https://hal.science/hal-02276688}

Submitted on 3 Sep 2019

HAL is a multi-disciplinary open access archive for the deposit and dissemination of scientific research documents, whether they are published or not. The documents may come from teaching and research institutions in France or abroad, or from public or private research centers.
L'archive ouverte pluridisciplinaire HAL, est destinée au dépôt et à la diffusion de documents scientifiques de niveau recherche, publiés ou non, émanant des établissements d'enseignement et de recherche français ou étrangers, des laboratoires publics ou privés. 


\title{
REVISITING ENTREPRENEURIAL RISK TAKING: COMBINED EFFECTS OF COGNITIVE HEURISTICS
}

\author{
SAULO D. BARBOSA \\ EMLYON Business School \\ 23, avenue Guy de Collongue \\ 69134 Ecully Cedex - France \\ $+33472184653$ \\ barbosa@em-lyon.com \\ ALAIN FAYOLLE \\ EMLYON Business School
}

\section{INTRODUCTION}

This paper examines how new information about a new venture project affects the risk perceptions associated with the project and the decision to join it. More specifically, we suggest that changes in the framing of the available information about a venture creation project alter risk perceptions associated with the project and people's willingness to join the project and start the venture.

We argue that additional information about a new venture can bias risk perceptions and decision making through two specific heuristics: availability and anchoring. Availability is the judgmental heuristic used when people assess the frequency of a class or the probability of an event by the ease with which instances or occurrences can be brought to mind (Hogarth, 1987; Tversky \& Kahneman, 1982). Anchoring is the cognitive bias that occurs when people make estimates by starting from an initial value that is adjusted to yield a final answer, adjustments being insufficient to compensate estimates' bias toward the initial values (Tversky et al., 1974).

Through an experiment, we show that availability and anchoring may have complementary or contradictory effects on risk perception, depending on the framing of new information. When the new information is framed in positive terms (i.e., in terms of potential gains and probabilities of success), both availability and anchoring contribute to reduce risk perception, enhancing people's willingness to join the new venture. However, when the new information is framed in negative terms (i.e., in terms of potential losses and probabilities of failure), availability and anchoring may have contradictory effects on risk perception - although availability of negatively framed information tends to increase the perceived risk associated with the new venture, anchoring may still reduce risk perception if the initial probabilities of failure are apparently small. This effect of perceived risk reduction seems to be reinforced by an effect of ambiguity reduction caused by the simple addition of new information, regardless the relevance of such information.

Taken together, these findings shed some new light on how cognitive heuristics may have combined effects that lead to the decision to start a new venture or not. Moreover, they illustrate how intuitive thinking-which seems to be well developed among entrepreneurs (Allinson, Chell, \& Hayes, 2000) - may actually lead to biased estimates that are subsequently used as a basis to make decisions. The very decision to become an entrepreneur seems to be considerably affected by these cognitive processes and may originate from biased estimates - which may help to explain, among other things, the high mortality rates new firms often face (Bates, 1990). 
In a nutshell, our findings suggest that risk perception and the decision to start a new venture, or to act upon an entrepreneurial opportunity, depends not only on asymmetries of information (as suggested by Janney \& Dess, 2006; Shane \& Vankataraman, 2000), but also on information processing - which is very contingent to the way information is presented.

\section{SUMMARY OF HYPOTHESES}

\section{Availability and Problem Framing: Effects on Risk Perception}

"Availability" is the judgmental heuristic used when people assess the frequency of a class or the probability of an event by the ease with which instances or occurrences can be brought to mind (Hogarth, 1987; Tversky et al., 1974, 1982). Availability may affect risk perception, because the ease with which people imagine or remember potential outcomes of a decision in a given situation may determine the perceived risk associated with the decision and the situation.

"Framing" refers to the judgmental heuristic used when people evaluate outcomes as deviations from reference points or aspiration levels, thereby "framing" them as losses or gains (Hogarth, 1987; Kahneman \& Tversky, 1979). Framing is also generally discussed in terms of the way a situation or a problem is presented, i.e., if the problem is framed in positive or negative terms (Sitkin \& Pablo, 1992). These two conceptions certainly overlap, and in this study we use the expression "problem framing" in a way that is consistent with both.

Nevertheless, the interactive role of problem framing and availability has yet to be explored in entrepreneurial settings. In particular, these heuristics may influence to a great extent one's evaluation of a new venture project, the risk perceptions associated with it, and, ultimately, one's decision to join the project or not. In this study we focus on risk perception, which corresponds to a decision maker's assessment of the risk inherent in a situation (Mullins \& Forlani, 2005; Sitkin \& Pablo, 1992). We also focus on the decision to start a new venture- or, more specifically, to join a new venture project. Since previous research has shown that lower levels of risk perception are generally associated with the decision to start a new venture, and may result from the use of cognitive biases (Keh et al., 2002; Simon et al., 2000), we expect that risk perception and the decision to start a business will be significantly affected by both availability and problem framing.

Thus, we hypothesize that the effect of available information on risk perception and decision making depends on whether this information is framed in positive or negative terms. New information framed in negative terms may enhance risk perception through availability, because the mere allusion to the potential negative outcomes of a decision may foster the recovering of other negative outcomes in memory and stimulate imaginability of undesirable consequences of the decision, enhancing fear (Slovic et al., 1982). Moreover, additional information concerning a new venture project influences the way in which the project is perceived. If this information is framed in negative terms, it may place the project below one's aspiration level, increasing the likelihood that the individual will frame the venture project as a loss vis-à-vis other projects that may represent more sure gains.

Hla: Availability of new information framed in negative terms (as chances of failure) increases the perceived risk associated with a new venture, reducing individuals' willingness to start the venture.

Inversely, additional information framed in positive terms may reduce the perceived risk associated with a new venture project, by enhancing optimism and stimulating perceptions of 
opportunities. Through availability, positively framed information may stimulate the retrievability of positive results of similar decisions in memory, fostering the imagination of desirable outcomes of the decision. Positively framed information may also reinforce the belief that the individual and the team are capable of accomplishing all the tasks necessary to the venture's success, enhancing perceptions of the project's feasibility and desirability, as well as the individual's and the team's perceived self-efficacy, risk taking, and entrepreneurial intentions (Krueger \& Dickson, 1994; Shepherd \& Krueger, 2002). This new information may also impact the way individuals frame the project, placing it above current aspiration levels and increasing its attractiveness vis-à-vis other projects.

$H 1 b$ : Availability of new information framed in positive terms (as chances of success)

decreases the perceived risk associated with a new venture, increasing individuals' willingness to start this venture.

\section{Anchoring and Problem Framing: Effects on Estimates of Probability of Success/Failure and on Risk Perception}

"Anchoring" is the phenomenon that occurs when people make estimates by starting from an initial value that is adjusted to yield a final answer, adjustments being insufficient to compensate estimates' bias toward the initial values (Tversky \& Kahneman, 1974). An interesting relation between anchoring and risk perception emerges when people evaluate conjunctive and disjunctive events. Probabilities of conjunctive events are often overestimated, whereas probabilities of disjunctive events are frequently underestimated. This has interesting implications when transposed to entrepreneurial situations, especially because the launch of a new venture can be framed both as a series of conjunctive or disjunctive events.

If we frame the entrepreneurial process that leads to the launch of a new venture in positive terms and as a series of conjunctive events, it is likely that the overall probability of success will be overestimated. This happens because "the successful completion of an undertaking, such as the development of a new product, typically has a conjunctive character: for the undertaking to succeed, each of a series of events must occur. Even when each of these events is very likely, the overall probability of success can be quite low if the number of events is large." (Tversky \& Kahneman, 1974)

$H 2 a$ : When the events necessary to the successful launch of a venture are framed in positive terms (high individual probabilities of success), individuals overestimate the venture's overall probability of success.

However, when the events necessary to the successful launch of a new venture are framed in negative terms (probabilities of failure) a structure very similar to a disjunctive one emerges. In a disjunctive structure, failure in one of the components may cause the failure of the entire structure. Typical examples of disjunctive structures are complex systems, such as a nuclear reactor or the human body, which will malfunction or even collapse if any of its essential components fails (Slovic et al., 1982; Tversky \& Kahneman, 1974). In disjunctive structures overall probabilities of failure are often underestimated, because the probabilities of failure of their components are usually small.

Now, if we frame the process of creating a new venture as a complex system in which each activity (raising initial funding, assuring a certain level of cash flow, etc.) is essential to the survival of the new firm, a structure similar to a disjunctive one emerges. This can be done by reversing the framing introduced in hypothesis $2 \mathrm{a}$, i.e., by presenting low probabilities of failure for each of the tasks necessary to the successful launch of the new venture. 
$H 2 b$ : When the events necessary to the successful launch of a venture are framed in negative terms (low individual probabilities of failure), individuals underestimate the venture's overall probability of failure.

Hypotheses $2 \mathrm{a}$ and $2 \mathrm{~b}$ concern anchoring effects on the estimates of the overall probability of success and failure of a new venture. However, anchoring may also have indirect effects on the risk perceptions associated with a new venture and the decision to start it or not. More specifically, both the overestimation of the overall probability of success (H2a) and the underestimation of the overall probability of failure $(\mathrm{H} 2 \mathrm{~b})$ contribute to a reduction of the perceived risk associated with the venture, enhancing the willingness to start it.

\section{RESEARCH DESIGN}

Participants completed a web-based survey in which they were presented four scenarios in a repeated-measures experimental design (Chow, 2002; Shadish, Cook, \& Campbell, 2002). In the introduction of each scenario, respondents were encouraged to put themselves vividly in each situation. All scenarios presented a situation where the respondent was invited by a friend to join him in the process of starting a new venture. In a 2 by 2 design, scenarios differed only in the current employment status of the respondent ("You just finished college and are looking for a job" versus "You have a job that gives you a reasonable salary and good perspectives of being promoted in the long run") and in the way the option of starting the venture was presented (emphasizing possible positive outcomes and the probability of success versus emphasizing possible negative outcomes and the probability of failure). In all scenarios, the probability of success/failure was "estimated by the friend" as "being around 50\%." Participants were then asked to indicate the level of risk they perceived in the option of joining the friend, and whether or not they would do it. After that, additional information was given for each scenario. The respondent was told that, after talking with the friend and reading his business plan, the estimated probability of:

- Having a prototype successfully developed (not having a prototype successfully developed) was $90 \%(10 \%)$;

- Receiving adequate funding (not receiving adequate funding) was $80 \%(20 \%)$;

- Having enough cash flow to stay in business (not having enough cash flow) was $85 \%$ $(15 \%)$;

- Being the first one in the market (arriving too late in the market) was $80 \%(20 \%)$.

Then, subjects were asked to consider this information and indicate the level of risk they now perceived in the option of joining the friend, and whether or not they would do it. In addition, they were asked to indicate the estimated probability of success (failure) of the new venture.

Although we used four scenarios in total, the additional information given after the first measurement of perceived risk always followed the initial description of the situation, i.e., scenarios initially described in positive terms received only additional information in positive terms, whereas scenarios that were initially described in negative terms received only additional information in negative terms. This is justified because we are interested in variations of perceived risk (and decisions) within each scenario, and not between scenarios. Thus, even though we used multiple scenarios, for the purposes of this study our approach is limited to a pretest-posttest design (Pedhazur \& Schmelkin, 1991).

\section{ANALYSIS}


We carry out the data analysis in three steps. First, we present some descriptive statistics and compare means of risk perception before and after additional information were provided. These basic statistics reveal that, in all scenarios, risk perception decreases after additional information about the new venture is provided. Second, in order to test hypotheses $1 \mathrm{a}$ and $1 \mathrm{~b}$, we use linear regression to assess the relative weigh of availability on risk perception changes relative to the venture project. In doing so, we show that even though risk perception decreases in all situations, it decreases significantly less when the additional information is framed in negative terms than when it is framed in positive terms. Finally, we test hypotheses $2 \mathrm{a}$ and $2 \mathrm{~b}$, concerning anchoring effects on the estimation of overall probabilities of success/failure of the new venture. Here, a simple t-test provides significant evidence that respondents' estimates are biased towards the initial values provided in the formulation of the problem.

\section{SUMMARY OF RESULTS AND DISCUSSION}

To sum up, the result of our experiment corroborate the hypotheses concerning the effects of availability and anchoring on risk perception and on estimates of overall probability of success/failure of venture creation. Our analyses show that the addition of negatively framed information about the venture project tends to increase perceived risk through availability, whereas the same heuristic tends to reduce perceived risk when additional information is framed in positive terms. Thus, availability effects depend on the framing of additional information.

Moreover, our results also show a significant effect of anchoring on the estimation of overall probabilities of success and failure of the new business. As expected, the vast majority of participants in our study failed to recognize the conjunctive and disjunctive structures underlying the events presented in the additional information. They therefore proceeded to an intuitive estimation of the overall probabilities of success and failure of the new venture. This intuitive estimation produced estimates that were clearly biased through anchoring.

The fact that risk perception decreased in all scenarios after the introduction of additional information suggests that anchoring effects overcame availability effects on perceived risk. This makes sense, since both the overestimation of the probability of success and the underestimation of the probability of failure contribute to the reduction of risk perception. Therefore, our findings show that anchoring and availability may have complementary and contradictory effects on risk perception and decision making, depending on information framing.

Nevertheless, our findings may also be interpreted in the light of two other cognitive mechanisms that may have come into play in our study: ambiguity reduction and an inside view of the problem. We discuss each mechanism in the following paragraphs.

Ambiguity reduction. Most theoretical analyses of decision making and risky choices depict each option as a gamble that can yield various outcomes with different probabilities (Rottenstreich \& Hsee, 2001). However, in real situations individuals are often faced with decisions and choices that must be made without complete knowledge of the potential outcomes of the decision and their respective probabilities. The extent to which an individual has information about potential outcomes of a decision and their probabilities determines different degrees of ambiguity, which are, in turn, related to the individual's behavior: several studies show that risk aversion increases with the ambiguity of the situation (Camerer et al., 1992). For instance, Hogarth \& Kunreuther (1995) show that individuals tend to take more risks when they know the potential outcomes of a decision and the probabilities associated with them than when they do not have this information - a phenomenon that is called ambiguity aversion. 
In our study, all scenarios initially presented a high degree of ambiguity: potential outcomes of the decision to start the new venture were not quantified and the initial probability of success/failure was "around 50\%." Thus, when individuals received additional information with specific probabilities attributed to clearly defined events (that were, in addition, supposed to come from a business plan), such additional information may have had an effect of ambiguity reduction, fostering risk taking through a decrease in risk perception. Note, however, that this apparent ambiguity reduction is completely illusory: the list of critical events provided is not exhaustive, the magnitude of potential outcomes remains unknown, and so does the industrial sector of the new business, its potential market, the product being developed, and many other characteristics of the new venture. Moreover, if the probabilities provided in the additional information had been taken into account analytically, risk perception would tend to increase, not decrease.

An inside view of the problem. Another cognitive mechanism that may have contributed to our results is the adoption of an inside view of the problem by the respondents. An inside view of the problem favors anchoring effects, because the forecasts and estimates are generated "by focusing on the case at hand, by considering the plan and the obstacles to its completion, by constructing scenarios of future progress, and by extrapolating current trends." (Kahneman \& Lovallo, 1993) In other words, an inside view of the problem anchors predictions on plans and scenarios. Hence, the adoption of an inside view of the problem by the participants in our study may have enhanced the impact of the additional information on their risk perceptions and decisions. Since this additional information asked respondents to imagine that they had talked with their friend and read his business plan, such information may have stimulated an inside view of the venture creation process. In this case, estimates are generally based on potential scenarios that are conceived by focusing exclusively on the case at hand, without any comparison with similar problems. Such estimates are generally overly optimistic.

\section{REFERENCES AVAILABLE FROM THE AUTHORS}


Copyright of Academy of Management Proceedings is the property of Academy of Management and its content may not be copied or emailed to multiple sites or posted to a listserv without the copyright holder's express written permission. However, users may print, download, or email articles for individual use. 
Copyright of Academy of Management Annual Meeting Proceedings is the property of Academy of Management and its content may not be copied or emailed to multiple sites or posted to a listserv without the copyright holder's express written permission. However, users may print, download, or email articles for individual use. 